\section{Información \\ Fuentes de información para el estudio de los poblados}

José Luis Gutiérrez Molina

Historiador

La colonización agraria en España tiene una larga trayectoria que se remonta al siglo XVIII. A mediados del XIX aparecen los primeros proyectos que, además que establecer nuevos núcleos de población, tratan de "colonizar" un territorio. Es decir, aumentar la población de una zona y, también, mejorar su explotación. Tenían un doble objetivo. De un lado, aumentar la riqueza y la producción agrícola y, de otro, resolver el problema social que representaba la miseria existente en el mundo rural sin poner en cuestión la estructura de la propiedad. Ambas metas fueron paulatinamente relacionándose con una política hidráulica que, mediante la transformación de secanos en regadio, aumentase la productividad, ordenase el espacio agrario y transformara la posesión de la tierra. Así, durante el primer tercio del siglo XX apareció el concepto "colonización integral" en el que se funden politicas hidráulicas, alternativas técnicas y parcelaciones. Era la alternativa a la Reforma Agraria.

Éstas fueron las líneas que inspiraron iniciativas como la Ley de Colonización y Repoblación Interior de 1907, las propuestas de los Congresos de Riegos de las décadas siguientes, la creación de las Confederaciones Hidrográficas durante la Dictadura del general Miguel Primo de Rivera o, finalmente, la Ley de Obras de Puestas en Riego de 1932 de la Segunda República. Aunque durante los años republicanos fuera la Reforma Agraria el proyecto de mayor repercusión social por incidir en la estructura de la propiedad, precisamente, la política colonizadora que puso en marcha el "Nuevo Estado" creado por los sublevados en julio de 1936, y desarrollado al completo tras su victoria en 1939, se presentó como una "rectificación" de la reforma agraria republicana. Aunque, en la práctica, no fue sino una ampliación de la llevada a cabo durante las dos décadas anteriores. En ella se potenciaron los aspectos técnicos y productivos frente a cualquier tentación social y estuvo plenamente subordinada a los intereses de los grandes propietarios.

El organismo que llevó a cabo este programa fue el Instituto Nacional de Colonización (INC) creado en octubre de 1939. Sustituyó al Servicio Nacional de Reforma Económica y Social de la Tierra que, durante la guerra, se hizo cargo de las explotaciones del IRA republicano. Más allá de los planteamientos ideológicos los rebeldes necesitaban mantener la actividad agrícola, vital para el desarrollo de las operaciones bélicas y abastecimiento de la retaguardia. El INC se hizo cargo de los planes de colonización en curso -los de la ley de 1907 y las parcelaciones de 1927- y de algunas de las fincas expropiadas durante la Segunda República en diversas provincias que no fueron devueltas a sus antiguos propietarios.

El INC existió durante más de treinta años hasta su sustitución, en 1971, por el Instituto de Reforma y Desarrollo Agrario (IRYDA). Du- rante tan dilatado espacio de tiempo el INC generó una importante masa documental, de diverso tipo, que proporciona un material de primera mano para la comprensión de uno de los procesos de transformación del espacio y la sociedad española más característicos de la dictadura de Franco. Aunque produjo una escasa redistribución social -unas 50.000 familias hasta 1971- sí realizó una intensa política de obras representada por los 11.000 kilómetros de acequias y canales, 113.000 hectáreas niveladas y los casi 300 pueblos nuevos.

El cuerpo principal de esta masa documental se conserva en el Ministerio de Agricultura, Pesca y Alimentación (MAPA), en el Archivo del Instituto de Reforma y Desarrollo Agrario depositado en San Fernando de Henares. También están disponibles, en distinto grado de catalogación y accesibilidad, los archivos de las Delegaciones Provinciales del INC.

Además, se encuentran disponibles los varios miles de negativos y positivos del material fotográfico realizado durante su larga vida. Un fondo que sirvió para ilustrar revistas como Colonización o Vida Nueva, editadas por el propio INC y que, también, fueron utilizadas profusamente en la prensa de esas décadas. El interés por la imagen del franquismo en general es lo que explica que, como en otros sectores productivos contemos con una abundante colección de películas, en distintos pasos, realizadas por el Departamento de Cinematografía del Ministerio de Agricultura. Unos fondos que se encuentran depositados en la Filmoteca Española. También NODO realizó un importante número de reportajes, desde su aparición en los años cuarenta hasta la década de los setenta. Cintas que así mismo, en formato vídeo, están disponibles para la consulta en el citado centro filmico.

Una fuente imprescindible para un primer acercamiento a la coIonización durante el franquismo son los cuatro volúmenes que recogen el trabajo realizado, durante la segunda mitad de los ochenta, por un equipo multidisciplinar por encargo de los ministerios de Administraciones Públicas, Agricultura, Pesca y Alimentación y Obras Públicas y Urbanismo. Gracias a ellos disponemos no sólo de una investigación completa sobre las distintas fases de la colonización en España sino también desde las diversas perspectivas que pueden ofrecer arquitectos, ingenieros, urbanistas, economistas, sociólogos, antropólogos o historiadores. Hoy día, la edición de Historia y Evolución de la Colonización Agraria en España (Madrid, 1988-1994, 4 vols.) -ver sección Bibliografía especializada en p. 124-125- está agotada y quizás fuera conveniente su reedición a tenor del creciente interés que despiertan estas cuestiones.

Pero, además, este trabajo nos ha dejado la inapreciable herencia de un fichero con las características de los poblados de colonización por cuenca hidrográfica; varios miles de microfotografías de los de las tipologías de sus equipamientos y viviendas y un conjunto de planos a escala 50.000. Un material de primerísima utilidad también hoy disponible en la Biblioteca General del MAPA en cuyos fondos bibliográficos, además, existen un gran número de cabeceras, bibliográficas y hemerográficas, de interés. De las revistas, además de las "históricas" editadas por el INC hay que destacar Agricultura y Sociedad en cuyas páginas encontramos numerosos artículos de interés. La edición existente en CD-Rom facilita su consulta. 